\title{
Correction to: Description and application of a method to quantify criterion-related cut-off values for questionnaire-based psychosocial risk assessment
}

\author{
Mathias Diebig ${ }^{1}\left[\right.$ [ $\cdot$ Peter Angerer ${ }^{1}$
}

Published online: 30 July 2021

(c) The Author(s) 2021

\section{Correction to: \\ International Archives of Occupational and \\ Environmental Health (2021) 94:475-485 \\ https://doi.org/10.1007/s00420-020-01597-4}

The article: Description and application of a method to quantify criterion-related cut-off values for questionnaire-based psychosocial risk assessment, written by Mathias Diebig, Peter Angerer was originally published electronically on the publisher's internet portal (currently SpringerLink) on 3 November 2021 without open access.

With the author(s)' decision to opt for Open Choice the copyright of the article changed on 15 August 2021 ( ) The Author(s) 2021 and the article is forthwith distributed under the terms of the Creative Commons Attribution 4.0 International License (http://creativecommons.org/licenses/by/4. $0 /$ ), which permits use, duplication, adaptation, distribution and reproduction in any medium or format, as long as you give appropriate credit to the original author(s) and the source, provide a link to the Creative Commons license and indicate if changes were made.

Open Access This article is distributed under the terms of the Creative Commons Attribution 4.0 International License (http://creativecommons.org/licenses/by/4.0/), which permits unrestricted use, distribution, and reproduction in any medium, provided you give appropriate credit to the original author(s) and the source, provide a link to the Creative Commons license, and indicate if changes were made.

The original article was corrected.

The original article can be found online at https://doi.org/10.1007/ s00420-020-01597-4.

Mathias Diebig

mathias.diebig@hhu.de

1 Institute of Occupational, Social and Environmental

Medicine, Heinrich Heine University Düsseldorf,

Universitätsstr. 1, 40225 Düsseldorf, Germany
Publisher's Note Springer Nature remains neutral with regard to jurisdictional claims in published maps and institutional affiliations. 